\title{
Factors contributing to psychological distress in the working population, with a special reference to gender difference - a population-based study
}

\section{Satu Viertiö ( $\sim$ satu.viertio@thl.fi )}

National Institute for Health and Welfare https://orcid.org/0000-0002-8894-2056

Olli Kiviruusu

Finnish Institute for Health and Welfare

\section{Maarit Piirtola}

University of Helsinki

Jaakko Kaprio

University of Helsinki

Tellervo Korhonen

University of Helsinki

\section{Mauri Marttunen}

Finnish Institute for Health and Welfare

Jaana Suvisaari

Finnish Institute for Health and Welfare

\section{Research article}

Keywords: Psychological distress, work-family conflict, gender, nationally representative study

Posted Date: November 4th, 2020

DOI: https://doi.org/10.21203/rs.3.rs-42789/v3

License: (c) (i) This work is licensed under a Creative Commons Attribution 4.0 International License. Read Full License

Version of Record: A version of this preprint was published at BMC Public Health on March 29th, 2021. See the published version at https://doi.org/10.1186/s12889-021-10560-y. 


\section{Abstract}

\section{Background}

Psychological distress refers to non-specific symptoms of stress, anxiety and depression, and it is more common in women. Our aim was to investigate factors contributing to psychological distress in the working population, with a special reference to gender differences.

\section{Methods}

We used questionnaire data from the nationally representative Finnish Regional Health and Well-being Study (ATH) collected in the years 2012-2016 (target population participants aged 20 +, n=96 668, response rate 53\%), restricting the current analysis to those persons who were working full-time and under 65 of age $(n=34468)$. Psychological distress was assessed using the Mental Health Inventory-5 (MHI-5) (cut-off value <=52). We studied the following factors potentially associated with psychological distress: sociodemographic factors, living alone, having children under18 years of age, lifestyle-related factors, social support, helping others outside of the home and work-related factors. We used logistic regression analysis to examine association between having work-family conflict with the likelihood for psychological distress. We first performed the models separately for men and women. Then interaction by gender was tested in the combined data for those independent variables where gender differences appeared probable in the analyses conducted separately for men and women.

Results

Women reported more psychological distress than men ( $11.0 \%$ vs. $8.8 \%$, respectively, $p<0.0001)$. Loneliness, job dissatisfaction and family-work conflict were associated with the largest risk of psychological distress. Having children, active participation, being able to successfully combine work and family roles, and social support were found to be protective factors. A significant interaction with gender was found in only two variables: ignoring family due to being absorbed in one's work was associated with distress in women (OR 1.30 (95\% Cl 1.00-1.70), and mental strain of work in men (OR 2.71 (95\% Cl 1.66-4.41).

Conclusions

Satisfying work, family life and being able to successfully combine the two are important sources of psychological well-being for both genders in the working population.

\section{Background}

Psychological distress refers to non-specific symptoms of stress, anxiety and depression. High levels of psychological distress are indicative of impaired mental health and may reflect common mental disorders, like depressive and anxiety disorders [1]. It is commonly measured with self-report rating scales like the General Health Questionnaire [2] or MHI-5, derived from the RAND-36 questionnaire [3]. As psychological distress also predicts sickness absences and work disability among the working-age population $[4,5]$, it is important to understand the factors that contribute to psychological distress among those who are working.

According to previous studies, women in the Western world are more prone to psychological distress, depression and anxiety than men [6-9]. Proposed explanations for the gender difference include biological, psychological and social risk factors $[10,11]$. Social factors involve, e.g. different societal roles and expectations for men and women. The roles at work and in the family as well as the challenges in combining them may be one factor contributing to gender 
differences [12-14]. However, the combination may also create more content and satisfaction in life, including with respect to possible gender differences [15].

Work-to-family conflict, family-to-work conflict and work-family enrichment load

Contradictions between work and family, a work-family conflict involves two separate, but related domains. One is work-to-family conflict, also called work-family interference or work interference with family, which occurs when participation in family life is made more difficult by work-related demands [16]. Family-to-work conflict, also called family-work interference or family interference with work, occurs when family life interferes with work [17]. In contrast, work-to-family enrichment means that the experiences at work improve one's performance and satisfaction within the family $[15,18]$. Role accumulation theory claims that multiple roles and meaningful content in life create a positive conception of oneself [19].

Work-family conflict has been found to be more common in women, although the gender difference in European countries is currently small [20]. Women still perform most of the domestic work in families [21]. Both having children and providing informal care to elderly relatives may increase the experience of work-family conflict [20]. One negative consequence of work-family conflict suggested by previous research is that women may reduce their contribution in work domain and that in turn may hinder career advancement [13]. According to European statistics, when the time spent travelling between home and the workplace and doing unpaid work are taken into account, women work on average 64 hours a week compared to 53 hours for men. Women spend on average 26 hours taking care of children and elderly relatives, whereas men spend only nine hours [22]. It seems that especially during parenting, women have more problems in coordinating work and family life [17, 23, 24].

According to a 2010 European Social Survey, mothers and higher educated employees report the highest rates of workfamily conflict [25]. Highly educated parents tend to experience more work-family conflict than less educated parents because of longer working days and greater difficulty in separating work from leisure time. A work position where an individual has much authority and responsibility for making decisions has been found to increase the risk of psychological distress [26].

Other work-related factors

According to a meta-analysis [27], a low level of job satisfaction is associated with a higher risk of psychological distress, burnout, anxiety and depression. Significant gender differences in job satisfaction have not been found, although women are less likely to work in managerial jobs and their salary is commonly lower [28, 29, 30].

Mental and physical work strain may affect mental health. Mental strain is common in human service work, but while working in these professions may increase the risk of emotional exhaustion and psychological distress, it may also provide meaning in work [31]. Physical work strain has been found to have a stronger effect on mental health in men than in women [32].

Social support, loneliness and other social environmental factors

Perceived social support refers to a person's sense that emotional or practical support is available from others when needed. A lack of social support from one's partner and close relatives, parents and friends is a risk factor for psychological distress [34]. There are indications that it operates in different ways for men and women [33], such as the fact that emotional support is more protective against depression for women than for men [34]. Women benefit from support more than men in both work and family contexts [35] and have more supportive networks than men do [36]. In contrast, women seem to receive less support from their spouses than men do from theirs [37].

Page $3 / 26$ 
Social support, especially emotional support, is often related to leisure-time activities, such as hobbies or cultural activities, and women tend to gain more benefit from social participation than men [34, 38]. It seems that leisure-time activities are associated with better mental health, especially when they include social contacts, and this is true particularly for men [39].

Emotional loneliness is the absence of someone to turn to in times of need, while social loneliness is the absence of a social network [40]. Loneliness, which women report experiencing more commonly than men in the general population, co-occurs with mental disorders and psychological distress [41, 42], and its association is partly independent of perceived social support [43]. Accordingly, emotional loneliness is more strongly associated with distress and mental disorders than social loneliness [42]. Among college students, loneliness has a greater impact on women's mental health than it does on men's [44], but differences between genders have not been found among community dwelling adults [45].

Marital status appears to be a significant feature in loneliness. Marriage, compared to widowhood and divorce, has been found to be associated with better mental well-being in both genders [46, 47], while becoming widowed has more long-term effects among men than among women [48]. Living alone has mostly been associated with a greater risk of experiencing mental health problems [49], in some studies particularly among men [50], and men especially experience greater mortality rates from mental disorders than do women [51]. However, findings, especially among elderly people, have also shown that living alone is not associated with reduced emotional well-being [52] or psychological distress [53].

Studies on parenting and mental health have mainly focused on how parental stress and depression affects children [54] and a depressed parent's behaviour as a parent [55]. Parenthood itself as a risk or protective factor has been studied less often. Some studies have found that parenthood is associated with less mental health problems [56,57], whereas no association between mental health and parenthood has been found when different types of family statuses, like single parenthood and divorce or living alone, have been taken into account [58].

\section{Other factors}

Harmful lifestyle factors, like smoking and heavy alcohol intake, have been found to be associated with an increased risk for depressive symptoms [59-62]. Cigarette smoking is more common in lower socioeconomic groups and among people with mental disorders [63]. The comorbidity of substance use disorders with anxiety and depressive disorders is nevertheless common, and it is partly explained by shared genetic liability $[64,65]$.

Financial difficulties have been found to be a risk factor for reduced mental health $[66,67]$. It is not just poverty that causes psychological distress, but also the stigma associated with receiving public assistance [68]. The risk of suffering common mental disorders, e.g. depression and anxiety disorders, among men and women appears different when viewed by income category; women's risk is greater than men's risk in all other categories except the lowest one, [69], whereas financial difficulties in covering household costs seem to have equal negative effects on mental health both in men and women $[70,71]$.

Informal caregiving, e.g. helping elderly parents, may increase psychological distress, and a recent study has found this to be true for women but not for men [72]. However, other studies have not found an association between informal caregiving and mental health [73].

Aims of the study 
The aim of the current study was to investigate factors contributing to psychological distress among those working full-time, with a special reference to gender differences. A large and representative general population-based survey sample was used, and variables were chosen in the regression models so that they would cover the most important domains that potentially influence psychological distress. Our hypothesis was that factors related to work, family and conflicts in their coordination would be particularly relevant for gender differences associated with psychological distress in the general population.

\section{Methods}

Design and population

The Regional Health, Wellbeing and Service Use Study (ATH) was set out to provide regional (regions or municipalities) information for monitoring on factors affecting health, wellbeing and service use in Finland. Several questions derived from the study are used as national indicators and reported in the Sotkanet portal (sotkanet.fi). Sotkanet portal provides demographic indicators across Finland and Europe on health, welfare and functioning of the service-system. The survey was targeted at the population of Finland aged 20 years or over, implemented annually from 2010 to 2016. Since 2017, the survey has been called Finsote and its content has changed slightly. A stratified random sampling design, described in detail by Härkänen et al. [74], was used, and the sampling was done without replacement. The sample was drawn from the Finnish Population Register. Participants were informed about the purposes of the survey, as well as about data security. In the selection phase of the new sample, there is the exclusion of persons who have been included into the samples of the ATH survey in previous years. Inverse probability weighting was used to account for missing data [74]. Data used in the present study are from nationally representative samples collected in the years 2012-2016 (n=96 668). In the present analyses, we used answers from participants aged 65 years or younger and who were working full-time $(n=34468)$ (Figure 1$)$. The respondents returned the questionnaire either by mail or online, and it was possible to answer in four languages: Finnish, Swedish, Russian and English. ATH study was approved by the Coordinating Ethics Committee of Finnish Institute for Health and Welfare (THL) in 2010 (approval number THL107/6.01.00/2010).

\section{Methods}

The questionnaire was designed by a group of scientists and specialists at the Finnish Institute for Health and Welfare with members from Finnish Institute of Occupational Health, the Social Insurance Institution of Finland and Institute of Criminology and Legal Policy.

Psychological distress was assessed using the MHI-5 [3, 5]. MHI-5 is derived from the RAND-36 questionnaire [3], which is a widely used self-report instrument to measure health-related quality of life. It includes eight concepts: physical functioning, bodily pain, role limitations due to physical health problems, role limitations due to personal or emotional problems, emotional well-being, social functioning, energy/fatigue, and general health perceptions [3]. The MHI-5 consists of five questions: 'How much of the time during the last month have you: 1) been a very nervous person, 2) felt downhearted and blue, 3) felt calm and peaceful, 4) felt so down in the dumps that nothing could cheer you up and 5) been a happy person? The six possible responses to the questions were scored between 1 and 6 . Items 3 and 5 ask about positive feelings and their scoring was done in reverse. All scores were then converted to fit a range from 0 to 100, with low scores indicating more psychological distress.

There is not one established cut-off point for measuring clinically significant psychological distress by MHI-5 [1]. We used the cut-off of 52 points, derived from the Eurobarometer survey in 2002 [75], in which Finland participated as 
well. The same cut-off score has been used throughout the history of the ATH study. ATH started regionally already in 2009. Cronbach's alpha, which is a measure of internal consistency, was 0.85 .

Work-related variables

Potential work-family conflict was assessed using the following question: 'Are the following statements about home and work accurate for you?' The respondents were then asked to agree or disagree with six statements. One statement was considered protective: 'I have more energy to be with the children when I also go to work'. Another statement was considered neutral: 'When I come home, I stop thinking about my work'. Work interference with family was assessed via three statements: 'I feel I am neglecting domestic issues because of my work', 'I sometimes ignore my family when I am wholly absorbed in my work' and 'I feel inadequacy as a parent'. Family interference with work was assessed with the statement 'I often find it difficult to concentrate on my work because of domestic issues'. The answers were divided into two classes: agree and disagree/cannot say.

Job satisfaction was measured using the following question: 'How satisfied are you with your present work?' The responses were divided into four categories: extremely satisfied, fairly satisfied, neither satisfied nor dissatisfied, and fairly/extremely dissatisfied. We merged classes 4 and 5 due to too few observations. Mental and physical strain of one's work was measured using the following question: 'What is/was you most recent job like (physically and mentally)?' Answers were divided into three categories: low strain (light, fairly light), moderate strain (a bit or quite strenuous) and high strain (very strenuous).

Questions related to job satisfaction and strain and work-family and family-work conflict are from the Finnish Quality of Work Life Surveys 1977-2008 [76].

Sociodemographic and other non-work-related variables

The age of the participants was divided into three categories: 20-34 years, 35-49 years and 50-65 years. Education was likewise divided into three categories: less or equal to 12 years, 13-16 years and 17 years or more. Marital status was categorised as married/cohabiting, separated/divorced/widowed and single. Having children under 18 years of age was divided into a yes or no category. Living alone was likewise categorised based on a response of yes or no. All the participants in the analyses had a full-time job.

Those who reported that they smoke on a daily basis were classified as smokers, others as non-smokers. Alcohol consumption was assessed using the Alcohol Use Disorders Identification Test (AUDIT-C) [77], which included the following questions: 'How often do you have a drink containing alcohol?', 'How many standard drinks of alcohol do you have on a typical day when you are drinking?', 'How often do you have 5 or more drinks on one occasion?'. A total score of six or more for men and five or more for women indicated at-risk drinking.

Subjectively experienced loneliness was divided into two categories: never/seldom/sometimes and often/all the time. Participation in leisure-time activities, such as hobby groups, societies and so forth, was categorised as regular or never/sometimes. Helping parents, children or other people outside the home regularly was defined as occurring at least once or twice a month.

Whether or not respondents received practical support when needed was identified using the following question: 'Who will provide practical help when you need it?' For emotional support, the question was worded as follows: 'Who do you believe truly cares about you, whatever may happen?'. Possible helpers or carers were partner, other next of kin, close friend, close colleague, close neighbours and other persons in close proximity to you. The answers were divided into three categories: no one helps or cares, 1-2 persons help or care, and 3-6 persons help or care. Financial problems 
were assessed with the question 'How difficult or easy is it to cover your living costs?'. The responses were divided into two categories: very difficult/fairly difficult and fairly easy/very easy.

Statistical analysis

Analyses were conducted using the SAS Enterprise Guide 7.1 [78] and SUDAAN Release 11.0.3. [79]. Weights were used to take into account the sampling design and non-participation, so that the results would be representative of the Finnish working-age population. We calculated the distribution of sociodemographic variables, other non-work-related variables and work-related variables for both genders. Gender differences in the categorical variables were tested using the two-tailed $\chi 2$ test. Next we calculated the prevalence of psychological distress in both genders according to the levels of the study variables.

We used logistic regression analysis to examine association between having family-to-work or work-to-family conflict with the likelihood for psychological distress (cut-off value of $\mathrm{MHI}-5<=52$ ). Dependent variable in the model was psychological distress (yes/ no) measured with MHI-5 and independent variables, i.e. sociodemographic factors, other non-work-related factors and work-related factors were included in the model simultaneously. We first performed the models separately for men and women. Then interaction by gender was tested in the combined data for those independent variables where gender differences appeared probable in the analyses conducted separately for men and women.

\section{Results}

Characteristics of study variables in men and women

Characteristics of the study variables are presented in Table 1 for men and women separately. Women reported more distress than men did, and with most of the other variables also exhibited a statistically significant gender difference. We found no gender difference for the variables living alone, having school-age children or being active in societies and hobby groups. Men and women differed in all but one work-family conflict: 'I have more energy to be with the children when I also go to work'.

Associations of study variables with psychological distress by gender

Cross-tabulation of different variables with psychological distress in men and women are presented in Table 2. Most of the independent variables were associated with psychological distress, but with some gender differences.

Education was associated with psychological distress only in women, with less education being associated with more distress. Helping a parent or a child outside of a person's own household was associated with less distress, but statistically significantly only in men helping a parent and in women helping a child. Helping somebody other than one's own child or parent was associated with more distress, but statistically significantly only in women.

Separate multivariable logistic regression analyses for men and women

Work-family conflicts were similarly either protective or risk factors in both genders (Table 3). Only one domain, 'I sometimes ignore my family when I am wholly absorbed in my work', was associated with psychological distress in women, but not in men. The most distressing domain in both genders was family-to-work conflict, 'I often find it difficult to concentrate on my work because of domestic issues', while the second most distressing was 'I feel inadequacy as a parent'. 
Being fairly or extremely dissatisfied with work had the strongest association with on psychological distress measure in both genders. The high mental strain of one's work had a statistically significant association with psychological distress only in men, whereas the physical strain of one's work was not associated with distress in either gender.

Of the other variables considered, loneliness was strongly associated with psychological distress among both genders. Smoking and difficulties in covering household costs were also similarly associated with psychological distress in both genders. With respect to other not work-related factors, having minor children and actively participating in hobby groups and societies were associated with lower odds, while feeling inadequacy as a parent was associated with higher odds for psychological distress.

Having someone to give practical help (among men) or emotional support (among women) when needed were both associated with lower odds of psychological distress, especially when several supporters were available. Helping others outside the home was not associated with psychological distress.

Combined logistic regression analysis to test for gender interactions

In the logistic regression models conducted separately for men and women, gender difference in the strength of the associations with psychological distress appeared possible in the following variables: having children under 18 years old, at-risk drinking, active participation, receiving practical help from others, receiving emotional support from others, mental strain of work and ignoring family when wholly absorbed in one's work. We included these variables in the logistic regression model pooled together across gender to test if they exhibited statistically significant gender interaction.

We found significant interaction by gender in two variables. The interaction term 'gender and mental strain' proved significant ( $F$ value 3.86, $p=0.0212$ ), indicating that mental strain was associated with psychological distress in men (see Table 3). The interaction term 'gender and ignoring family due to being absorbed in one's work' also proved significant ( $F$ value 4.16, $p=0.0414$ ), indicating that ignoring family due to being absorbed in one's work was associated with psychological distress in women.

\section{Discussion}

In this cross-sectional, nationally representative study sample of the working population, we found that several factors related to work and balancing work and family life are associated with psychological distress. Furthermore, these associations were mostly similar among women and men. Earlier studies have yielded mixed evidence regarding gender differences based on work-family conflicts [80].

Psychological distress is quite common problem. In the current study, $11 \%$ of women and $8.8 \%$ of men in the working population had psychological distress. In the most recent national FinSote Survey from years 2017-2018, where participants were over 19 years with no upper age limit, the prevalence of psychological distress among women was $11.9 \%$ and among men $11.2 \%$ [81], suggesting that people who are employed full-time may experience slightly less psychological distress than the rest of the population. In large surveys made in the United States, $15.1 \%$ reported moderate psychological distress and 3.1\% severe distress over the 2001-2012 period [82]. Because of the different rating scales and cut-off scores used in previous studies, the reported prevalence figures of psychological distress are not directly comparable between countries. With the cut-off score used in the current study, some underlying mood or anxiety disorder is very probable [1]. 
Family-to-work conflict has previously been found to be less common than work-to-family conflict [83], but in our study family-to-work conflict was more strongly associated with psychological distress than work-to-family conflict. The only gender difference was found in sometimes ignoring family when wholly absorbed in one's work, which was associated with psychological distress only in women. This suggests that an engaging job may cause psychological distress via work-to-family conflict among women [84]. Difficulty in concentrating on work because of domestic issues showed the strongest association with psychological distress, but it could also imply that the participants were experiencing distressing family-related challenges at the time.

We also found evidence of work-to-family enrichment: those who responded that they have more energy to be with their children when they also go to work had less psychological distress [15]. Also, participants who reported that they stop thinking about their work when they come home had less distress, suggesting that a successful combination of work and family life protects a person from psychological distress. Inadequacy as a parent was associated with psychological distress independently of gender. Prior studies have reported that about half of employed parents feel they do not spend enough time with their children, and such a time deficit is associated with psychological distress [85].

Interestingly, mental strain of one's work was a risk for psychological distress in men but not in women. The link between the mental demands of one's work and psychological distress or mental disorder has been observed both in cross-sectional and in longitudinal studies [86-88]. Emotional exhaustion is more common in emotionally demanding jobs, such as in police work or among physicians and other professionals working in healthcare, and effective preventive interventions are available [89]. Most previous studies have not found any gender difference in how the psychological or emotional demands of one's work affect mental health, but one previous study found that they may have a mediating effect between low income and psychological distress in men [90].

Consistent with prior studies [27, 91], our findings showed that job dissatisfaction was strongly associated with psychological distress. We did not find any gender difference in terms of job dissatisfaction, which is consistent with earlier studies $[29,92]$. In a meta-analysis on the health effects of job dissatisfaction, the strongest correlation between job dissatisfaction and mental health problems was with burnout [27]. Burnout is a chronic stress syndrome characterised by exhaustion, cynicism and a lack of professional efficacy [93], and it may be an important mediator in the observed association between job dissatisfaction and psychological distress.

Loneliness was, similar to job dissatisfaction, the most significant factor increasing the odds of psychological distress, and at the same magnitude, in both genders. Women reported feelings of loneliness more often than men, as has been found earlier [41], but the association with psychological distress was equal in both genders. Previous studies have shown that loneliness is a significant risk factor for depression [94] and other common mental disorders [43] as well as for suicidal ideation and suicide attempts [95]. Furthermore, loneliness is associated with an increased risk of many health problems [95], and it has been increasingly seen as an important public health problem [96]. Our finding supports this view and encourages experts to implement specific interventions to reduce loneliness [97].

Various aspects related to social networks and social support were associated with having less psychological distress. Having minor children, being active in hobby groups, and receiving social support when needed were all associated with less psychological distress. Previous studies have found that social participation in activities is especially beneficial for women [34, 38], whereas men and women benefit differently from emotional support [33-35]. However, while the analyses conducted separately among men and women suggested that there might be gender differences in these aspects of social networks and support, we did not observe any significant interaction in the analysis. It is also noteworthy that helping others outside the home was not associated with psychological distress. 
Previous studies $[66,68,70]$ have likewise found that financial difficulties constitute a notable risk factor for psychological distress. Consistent with a large body of previous research, smoking $[59,98,99]$ and at-risk drinking $[100,101]$ were associated with more psychological distress; however, their effect was less prominent than that of social and work-related factors in our study.

After considering a wide range of work-related, family-related and social factors, well-known risk factors like marital status and living alone did not have an association with psychological distress. This is consistent with a previous study that found that loneliness is a mediator between living alone and distress [102].

Strengths and limitations

The major strength of the present study is the large study sample representative of the adult working-age population in Finland. It was possible for participants to respond in several languages spoken by sizeable minorities within Finland, which further improved the representativeness. The Finnish version of MHI-5 has been shown to have construct validity [103].

The major limitation is that our study is cross-sectional. Therefore, we could not assess the direction or causality of the associations. Furthermore, data were obtained using self-report questionnaire and therefore we did not get detailed information e.g. about mental disorders. Self-reporting bias, such as social desirability bias and recall bias, could affect the results [104]. We did not have information about job demands, job control or other features related to work. Low response rate is a common phenomenon in survey studies today, and so it was in our study as well, especially for the youngest age group. However, we used inverse probability weighting to account for missing data, which has been shown to remove a relatively large proportion of the bias related to the low response rate in the current study sample [74].

\section{Conclusions}

Satisfying work, family life and being able to successfully combine both are important sources of psychological wellbeing in the working population, both among men and women. Moreover, our findings support the notion of loneliness as a major public health problem.

\section{Declarations}

Ethics approval and consent to participate

The ATH Study was approved by the Coordinating Ethics Committee of Finnish Institute for Health and Welfare (THL) in 2010 (approval number THL107/6.01.00/2010).

Consent for publication

Not applicable.

Availability of data and materials

The data that support the findings of this study are not publicly available. The data, from which all personal data have been eliminated, may be disclosed for research purposes by FinData in return for a research proposal and an approved user authorisation application.

Competing interests

Page 10/26 
The authors declare that they have no competing interests.

Funding

Academy of Finland (grant No. 312073 to JK, grant No. 309119 to TK and grant No. 309117 to MM). The funding body had no role in the design of the study and collection, analysis, and interpretation of data and in writing the manuscript.

Authors' contributions

All authors contributed to the study conception and design. The statistical analysis plan was designed by SV and JS, and material preparation and statistical analysis was done by SV. The first draft of the manuscript was written by SV, and all authors commented on previous versions of the manuscript. All authors read and approved the final manuscript.

Acknowledgements

Not applicable.

Authors' information

Satu Viertiö 1,4, Olli Kiviruusu 1,4, Maarit Piirtola 2, Jaakko Kaprio 2,3, Tellervo Korhonen 2, Mauri Marttunen 1,4, Jaana Suvisaari 1.

1 Finnish Institute for Health and Welfare in Finland (THL), Department of Public Health Solutions, Helsinki, Finland

2 University of Helsinki, Institute for Molecular Medicine Finland (FIMM), Helsinki, Finland

3 University of Helsinki, Department of Public Health, Helsinki, Finland

4 University of Helsinki and Helsinki University Hospital, Adolescent psychiatry, Helsinki, Finland

Corresponding author: Satu Viertiö, satu.viertio@thl.fi

\section{Abbreviations}

ATH: Finnish Regional Health and Well-being Study

MHI-5: Mental Health Inventory-5

OR: odds ratio

AUDIT-C: The Alcohol Use Disorders Identification Test

Cl: confidence interval

\section{References}

1. Cuijpers P, Smits N, Donker T, ten Have M, de Graaf R. Screening for mood and anxiety disorders with the five-item, the three-item, and the two-item Mental Health Inventory. Psychiatry Res. 2009;15:168:250-5.

2. Goldberg DP. The Detection of Psychiatric Illness by Questionnaire. London: Oxford University Press; 1972. 
3. McHorney CA \& Ware JE Jr. Construction and validation of an alternate form general mental health scale for the Medical Outcomes Study Short-Form 36-Item Health Survey. Med Care. 1995;33:15-38.

4. Mauramo E, Lahti J, Lallukka T, Lahelma E, Pietiläinen O, Rahkonen O. Changes in common mental disorders and diagnosis-specific sickness absence: a register-linkage follow-up study among Finnish municipal employees. Occup Environ Med. 2019;76:230-235.

5. Hiilamo A, Shiri R, Kouvonen A, Mänty M, Butterworth P, Pietiläinen O, Lahelma E, Rahkonen O, Lallukka T. Common mental disorders and trajectories of work disability among midlife public sector employees - A 10-year follow-up study. J Affect Disord. 2019;247:66-72.

6. Markkula N, Suvisaari J, Saarni SI, Pirkola S, Pena S, Saarni S, Ahola K, Mattila AK, Viertiö S, Strehle J, Koskinen S, Härkänen T. Prevalence and correlates of major depressive disorder and dysthymia in an eleven-year follow-up Results from the Finnish Health 2011 Survey. J Affect Disord. 2015;173:73-80.

7. Piccinelli M and Wilkinson G. Gender differences in depression: Critical review. Br J Psychiatry. 2000;177:486-92.

8. Bromet E, Andrade LH, Hwang I et al. Cross-national epidemiology of DSM-IV major depressive episode. BMC Med. 2011;9:90.

9. Suvisaari J, Aalto-Setala T, Tuulio-Henriksson A, Härkänen T, Saarni SI, Perälä J, Schreck M, Castaneda A, Hintikka J, Kestilä L, Lähteenmäki S, Latvala A, Koskinen S, Marttunen M, Aro H, Lönnqvist J. Mental disorders in young adulthood. Psychol Med. 2009;39:287-299.

10. Kuehner C. Gender differences in unipolar depression: an update of epidemiological findings and possible explanations. Acta Psychiatr Scand. 2003;108:163-174.

11. Hopcroft RL, Bradley DB. The Sex Difference in Depression Across 29 Countries. Social Forces. 2007;85:14831507.

12. Beauregard N, Marchand A, Blanc M-E. What do we know about the non-work determinants of worker's mental health? A systematic review of longitudinal studies. BMC Public Health. 2011;11:439.

13. Marchand A, Bilodeau J, Demers A, Beauregard N, Durand P, Hines Victor Y III. Gendered depression: Vulnerability or exposure to work and family stressors? Soc Sci Med. 2016;166:160-168.

14. Amstad FT, Meier LL, Fasel U, Elfering A, Semmer NK. A meta-analysis of work-family conflict and various outcomes with a special emphasis on cross-domain versus matching-domain relations. J Occup Health Psych. 2011;16:151-169.

15. Greenhaus JH and Powell GN. When work and family are allies: a theory of work-family enrichment. Acad Manage Rev. 2006;31:72-92.

16. Nilsen W, Skipstein A, Østby, KA, Mykletun A. Examination of the double burden hypothesis - a systematic review of work-family conflict and sickness absence. Eur J Public Health. 2017;27:465-471.

17. Byron K. A meta-analytic review of work-family conflict and its antecedents. J Vocat Behav. 2005;67:69-198.

18. Xu S, Wang Y, Mu R, Jin J, Gao F. The effects of work-family interface on domain-specific satisfaction and wellbeing across nations: The moderating effects of individualistic culture and economic development. Psych J. 2018;7:248-267.

19. Sieber SD. Toward a Theory of Role Accumulation. Am Sociol Rev. 1974;39:567-578.

20. Remery C, Schippers J. Work-Family Conflict in the European Union: The Impact of Organizational and Public Facilities. Int J Environ Res Public Health. 2019;16:4419.

21. Cunha M, Andre S, Aparicio G, Santos E, Nunes C, Students do 23 CLE. Organization of housework in heterosexual couples: systematic review of the literature. Procedia Soc Behav Sci. 2016;217:459-68. 
22. European Union. Differences in men's and women's work, care and leisure time. Policy Department for Citizen's Rights and Constitutional Affairs. 2016 https://www.europarl.europa.eu/RegData/etudes/STUD/2016/556933/IPOL_STU(2016)556933_EN.pdf

23. Lunau T, Bambra C. Eikemo TA, van der Wel KA, Dragano N. A balancing act? Work-life balance, health and wellbeing in European welfare states. Eur J Public Health. 2014;24:422-427.

24. Eby LT, Casper WJ, Lockwood A, Bordeaux C, Brinley A. Work and family research in IO/OB: Content analysis and review of the literature (1980-2002) J Vocat Behav. 2005;66:124-197.

25. Notten N, Grunow D, Verbakel E. Social Policies and Families in Stress: Gender and Educational Differences in Work-Family Conflict from a European Perspective. Soc Indic Res. 2017;132:1281-1305.

26. Marchand A, Demers A, Durand P. Do occupation and work conditions really matter? A longitudinal analysis of psychological distress experiences among Canadian workers. Sociol Health III. 2005;27:602-627.

27. Faragher EB, Cass M, Cooper CL. The relationship between job satisfaction and health: a meta-analysis. Occup Environ Med. 2003;62:105-12.

28. Brush DH, Moch MK, Pooyan A. Individual demographic differences in job satisfaction. J Occup Behav. 1987;8:139-156.

29. Witt LA and Nye LG. Gender and the Relationship Between Perceived Fairness of Pay or Promotion and Job Satisfaction. J Appl Psychol. 1992;77:910-917.

30. Greenhaus JH, Parasuraman S, Wormley WM. Effects of Race on Organizational Experiences, Job Performance Evaluations, and Career Outcomes. Acad Manage J. 1990;33:64-86.

31. Geisler M, Berthelsen H, Hakanen JJ. No Job Demand Is an Island - Interaction Effects Between Emotional Demands and Other Types of Job Demands. Front Psychol. 2019;10:873.

32. Hiesinger K, Tophoven S. Job requirement level, work demands, and health: a prospective study among older workers. Int Arch Occ Env Hea. 2019;92:1139-1149.

33. Stansfeld SA, Fuhrer R, Shipley MJ. Types of social support as predictors of psychiatric morbidity in a cohort of British Civil Servants (Whitehall II Study). Psychol Med 1998;28:881-92.

34. Kendler KS, Myers J, Prescott CA. Sex Differences in the Relationship Between Social Support and Risk for Major Depression: A Longitudinal Study of Opposite-Sex Twin Pairs. Am J Psychiatry. 2005;162:250-256.

35. Perrewé, PL, Carlson DS. Do men and women benefit from social support equally? Results from a field examination within the work and family context. In: D. L. Nelson \& R. J. Burke, editors. Gender, work stress, and health. New York: APA; 2002. p. 101-114.

36. Belle D. Gender differences in the social moderators of stress, in Gender and Stress. J Appl Psychol. 1988;70:157-277.

37. Schwarzwer R, Gutierrez-Dona B. More spousal support for men than for women: a comparison of sources and types of support. Sex Roles. 2005;52:523-532.

38. Amagasa S, Fukushima N, Kikuchi H, Oka K, Takamiya T, Odagiri Y, Inoue S. Types of social participation and psychological distress in Japanese older adults: A five-year cohort study. PLoS ONE. 2017;12: 12(4):e0175392

39. Takeda F, Noguchi H, Monma K, Tamiya N. How Possibly Do Leisure and Social Activities Impact Mental Health of Middle-Aged Adults in Japan?: An Evidence from a National Longitudinal Survey. PLoS ONE 2015 Oct 2;10(10):e0139777.

40. Weiss R.S. Loneliness: The experience of emotional and social isolation. Cambridge: MIT Press; 1973.

41. Beutel ME, Klein EM, Brähler E, Reiner I, Jünger C, Michal M, Wiltink J, Wild PS, Münzel T, Lackner KJ, Tibubos AN. Loneliness in the general population: prevalence, determinants and relations to mental health. BMC Psychiatry. 
2017;17:97.

42. Hyland P, Shevlin M, Cloitre M, Karatzias T, Vallieres F, McGinty G, Fox R, McHugh Power J. Quality not quantity: Ioneliness subtypes, psychological trauma, and mental health in the US adult population. Soc Psychiatry Psychiatr Epidemiol. 2019;54:1089-1099.

43. Nuyen J, Tuithof M, de Graaf R, van Dorsselaer S, Kleinjan M, ten Have M. The bidirectional relationship between loneliness and common mental disorders in adults: findings from a longitudinal population-based cohort study. Soc Psychiatry Psychiatr Epidemiol 2019 Sep 19 (Online ahead of print).

44. Liu H, Zhang M, Yang Q, Yu B. Gender differences in the influence of social isolation and loneliness on depressive symptoms in college students: a longitudinal study. Soc Psychiatry Psychiatr Epidemiol. 2020;55(2):251-257.

45. Lee EE, Depp C, Palmer BW, Glorioso D. High prevalence and adverse health effects of loneliness in communitydwelling adults across the lifespan: role of wisdom as a protective factor. Int Psychogeriatr. 2018;31:1447-1462.

46. Ben-Zur H. Loneliness, optimism, and well-being among married, divorced, and widowed individuals. J Psychol. 2018;146:23-36.

47. Scott KM, Wells JE, Angermeyer $M$ et al. Gender and the relationship between marital status and first onset of mood, anxiety and substance use disorders. Psychol Med. 2010;9:1495-1505.

48. Kaprio J, Koskenvuo M, Rita H. Mortality after bereavement: a prospective study of 95,647 widowed persons. Am J Public Health. 1987;77(3):283-7.

49. Pulkki-Råback L, Kivimäki M, Ahola K, Joutsenniemi K, Elovainio M, Rossi H, Puttonen S, Koskinen S, Isometsä E, Lönnqvist J, Virtanen M. Living alone and antidepressant medication use: a prospective study in a working-age population. BMC Public Health. 2012;12:236.

50. Joutsenniemi K, Martelin T, Martikainen P, Pirkola S, Koskinen S. Living arrangements and mental health in Finland. J Epidemiol Commun H. 2005;60:468-475.

51. Koskenvuo M, Kaprio J, Lönnqvist J, Sarna S. Social factors and the gender difference in mortality. Soc Sci Med. 1986;23:605-9. https://doi.org/10.1016/0277-9536(86)90154-1

52. Kawamoto R, Yoshida O, Oka Y, Kodama A. Influence of living alone on emotional well-being in communitydwelling elderly persons. Geriatr Gerontol Int. 2005;3:152-158.

53. Michael YL, Berkman LF, Colditz GA, Kawachi I. Living Arrangements, Social Integration, and Change in Functional Health Status. Am J Epidemiol . 2001;153:123-131.

54. Pietikäinen JT, Kiviruusu O, Kylliäinen A, Pölkki P, Saarenpää-Heikkilä O, Paunio T, Paavonen EJ. Maternal and paternal depressive symptoms and children's emotional problems at the age of 2 and 5 years: a longitudinal study. J Child Psychol Psychiatry. 2020;61:195-204.

55. Wilson S and Burdin E. Effects of paternal depression on fathers' parenting behaviors: a meta-analytic review. Clin Psychol Rev. 2010;30:167-180.

56. Helbig S, Lampert T, Klose M, Jacobi F. Is parenthood associated with mental health? Findings from an epidemiological community survey. Soc Psychiatry Psychiatr Epidemiol. 2006;41:889-896.

57. Mckenzie SK, Carter K. Does transition into parenthood lead to changes in mental health? Findings from three waves of a population based panel study. J Epidemiol Commun H. 2012;67:339-345.

58. Rimehaug T, Wallander J. Anxiety and depressive symptoms related to parenthood in a large Norwegian community sample: the HUNT2 study. Soc Psychiatry Psychiatr Epidemiol. 2010;45: 713-721.

59. Ranjit A, Korhonen T, Buchwald J, Heikkilä K, Tuulio-Henriksson A, Rose RJ, Kaprio J, Latvala A. Testing the reciprocal association between smoking and depressive symptoms from adolescence to adulthood: $A$ longitudinal twin study. Drug Alcohol Depen. 2019;200:64-70.

Page $14 / 26$ 
60. Grant BF, Stinson FS, Dawson DA, Chou P, Dufour MC, Compton W, Pickering RP, Kaplan K. Prevalence and Cooccurrence of Substance Use Disorders and Independent Mood and Anxiety Disorders. Arch Gen Psychiatry. 2004;61:807-816.

61. Li J, Wang H, Li M, Shen Q, Li X, Zhang Y, Peng J, Rong X, Peng Y. Effect of Alcohol Use Disorders and Alcohol Intake on the Risk of Subsequent Depressive Symptoms: A Systematic Review and Meta-Analysis of Cohort Studies. Addiction. 2019 (Online ahead of print).

62. Berg NJ, Kiviruusu OH, Lintonen TP. Longitudinal prospective associations between psychological symptoms and heavy episodic drinking from adolescence to midlife. Scand J Public Health 2019;47:420-427.

63. Drope J, Liber AC, Cahn Z, Stoklosa M, Kennedy R, Douglas CE, Henson R, Drope J. Who's still smoking? Disparities in adult cigarette smoking prevalence in the United States. Ca-Cancer J Clin. 2018;2:106-115.

64. Virtanen S, Kuja-Halkola R, Mataix-Cols D, Jayaram-Lindström N, D'Onofrio BM, Larsson H, Rück C, Suvisaari J, Lichtenstein P, Latvala A. Comorbidity of substance misuse with anxiety-related and depressive disorders: a genetically informative population study of 3 million individuals in Sweden. Psychol Med. 2019;22:1-10 (Online ahead of print).

65. Brainstorm consortium, Anttila V, Bulik-Sullivan B et al. Analysis of shared heritability in common disorders of the brain. Science. 2018;22:360(6395).

66. Nagasu M, Kogi K, Yamamoto I. Association of socioeconomic and lifestyle-related risk factors with mental health conditions: a cross-sectional study. BMC Public Health. 2019;19:1759.

67. Holden L, Ware RS, Lee C. Trajectories of mental health over 16 years amongst young adult women: The Australian Longitudinal Study on Women's Health. Dev Psychol. 2016;52:164-75.

68. Hansen H, Bourgois P, Drucker E. Pathologizing poverty: New forms of diagnosis, disability, and structural stigma under welfare reform. So Sci Med. 2014;103:76-83.

69. The NHS Information Centre for health and social care. Adult psychiatric morbidity in England 2007. Results of a household survey. UK. 2009. https://files.digital.nhs.uk/publicationimport/pub02xxx/pub02931/adul-psyc-morbres-hou-sur-eng-2007-rep.pdf

70. Ahnquist J, Wamala SP. Economic hardships in adulthood and mental health in Sweden. The Swedish National Public Health Survey 2009. BMC Public Health. 2011;11:788.

71. Economou M, Peppou LE, Souliotis K, Konstantakopoulos G, Papaslanis T, Kontoangelos K, Nikolaidi S, Stefanis N. An association of economic hardship with depression and suicidality in times of recession in Greece.

Psychiatry Res. 2019;279:172-179.

72. Lacey RE, McMunn A, Webb E. Informal caregiving patterns and trajectories of psychological distress in the UK Household Longitudinal Study. Psychol Med. 2018;49:1652-1660.

73. Hajek A, König H-H. The relation between personality, informal caregiving, life satisfaction and health-related quality of life: evidence of a longitudinal study. Qual Life Res. 2018;27:1249-1256.

74. Härkänen T, Kaikkonen R, Virtala E, Koskinen S. Inverse probability weighting and doubly robust methods in correcting the effects of non-response in the reimbursed medication and self-reported turnout estimates in the ATH survey. BMC Public Health. 2014;14:1150.

75. The European Opinion Research Group. The mental health status of the European population. Directorate-General Press and Communication "Opinion Polls, Press Reviews, Europe Direct". 2003.

https://www.mscbs.gob.es/organizacion/sns/planCalidadSNS/pdf/excelencia/salud_mental/opsc_est19.pdf.pdf

76. Lehto AM, Sutela H. Three decades of working conditions. Findings of Finnish Quality of Work Life Surveys 1977-2008. Statistics Finland 2009. Available at

Page $15 / 26$ 
https://www.stat.fi/tup/julkaisut/tiedostot/working_conditions.pdf.

77. Bush K, Kivlahan DR, McDonell MB, Fihn SD, Bradley KA. The AUDIT alcohol consumption questions (AUDIT-C): an effective brief screening test for problem drinking. Ambulatory Care Quality Improvement Project (ACQUIP). Alcohol Use Disorders Identification Test. Arch Intern Med. 1998;158:1789-95.

78. SAS Institute Inc. Cary, North Carolina, USAResearch Triangle Institute.

79. SUDAAN User's Manual, Release 9.0. Research Triangle Park, NC. 2004.

80. Eby LT, Casper WJ, Lockwood A, Bordeaux C, Brinley A. Work and family research in IO/OB: Content analysis and review of the literature (1980-2002) J Vocat Behav. 2005;66:124-197.

81. Parikka S, Pentala-Nikulainen $\mathrm{O}$, Koskela T, Kilpeläinen H, Ikonen J, Aalto A-M, Muuri A, Koskinen S \& Lounamaa A. Kansallisen terveys-, hyvinvointi ja palvelututkimus FinSoten perustulokset 2017-2018. Available in Finnish at: thl.fi/finsote

82. Mojtabai R, Jorm AF. Trends in psychological distress, depressive episodes and mental health treatment-seeking in the United States: 2001-2012. J Affect Disord. 2015;174:556-561.

83. Kelly EL, Moen P, Oakes JM, Fan W, Okechukwu C, Davis KD, Hammer L, Kossek E, King RB, Hanson G, Mierzwa F, Casper L. Changing Work and Work-Family Conflict: Evidence from the Work, Family, and Health Network. Am Sociol Rev. 2014;79(3):485-516.

84. Shimazu A, Schaufeli WB, Kubota K, Watanabe K, Kawakami N. Is Too Much Work Engagement Detrimental? Linear or Curvilinear Effects on Mental Health and Job Performance. PLoS One. 2018;26;13(12):e020868.

85. Milkie MA, Nomaguchi K, Schieman S. Time Deficits with Children: The Link to Parents' Mental and Physical Health. Soc Ment Health. 2018;9:277-295.

86. Rivière M, Leroyer A, Ferreira Carreira L, Blanchon T, Plancke L, Melchior M, Younès N. Which work-related characteristics are most strongly associated with common mental disorders? A cross-sectional study. BMJ Open. 2018;8(8):e020770.

87. Wieclaw J, Agerbo E, Mortensen PB, Burr H, Tuchsen F, Bonde JP. Psychosocial working conditions and the risk of depression and anxiety disorders in the Danish workforce. BMC Public Health. 2008;8:280.

88. Niedhammer I, Malard L, Chastang JF. Occupational factors and subsequent major depressive and generalized anxiety disorders in the prospective French national SIP study. BMC Public Health. 2015;15:200.

89. West CP, Dyrbye LN, Erwin PJ, Shanafelt TD. Interventions to prevent and reduce physician burnout: a systematic review and meta-analysis. Lancet. 2016;388(10057):2272-2281.

90. Duchaine CS, Ndjaboué R, Levesque M, Vézina M, Trudel X, Gilbert-Ouimet M, Dionne CE, Mậsse B, Pearce N, Brisson C. Psychosocial work factors and social inequalities in psychological distress: a population-based study. BMC Public Health. 2017;17:91.

91. Kenny DT, Carlson JG, McGuigan FJ, Sheppard JL. Stress and health: Research and clinical applications. Amsterdam: Harwood Academic Publishers; 2000.

92. D'Arcy C, Syrotuik J, Siddique CM. Perceived job attributes, job satisfaction, and psychological distress: A comparison or working men and women. Hum Relat. 1984;37:603-611.

93. Ahola K, Honkonen T, Isometsä E, Kalimo R, Nykyri E, Koskinen S, Aromaa A, Lönnqvist J. Burnout in the general population. Results from the Finnish Health 2000 Study. Soc Psychiatry Psychiatr Epidemiol. 2006;41:11-7.

94. Erzen E, Çikrikci Ö. The effect of loneliness on depression: A meta-analysis. Int J Soc Psychiatry. 2018;64:427435.

95. Leigh-Hunt N, Bagguley D, Bash K, Turner V, Turnbull S, Valtorta N, Caan W. An overview of systematic reviews on the public health consequences of social isolation and loneliness. Public Health. 2017;152:157-171. 
96. Cacioppo JT, Cacioppo S. The growing problem of loneliness. Lancet. 2018;391(10119):426.

97. Masi CM, Chen HY, Hawkley LC, Cacioppo JT. A meta-analysis of interventions to reduce loneliness. Pers Soc Psychol Rev. 2011;5:219-66.

98. Fluharty M, Taylor AE, Grabski M, Munafo MR. The Association of Cigarette Smoking With Depression and Anxiety: A Systematic Review. Nicotine \& Tobacco Research. 2017;19:3-13.

99. Royal College of Physicians, Royal College of Psychiatrists. Smoking and mental health. London: RCP; 2013.

100. Haarasilta LM, Marttunen MJ, Kaprio JA, Aro HM. Correlates of depression in a representative nationwide sample of adolescents (15-19 years) and young adults (20-24 years). Eur J Public Health. 2004;14:280-5.

101. Edwards AC, Sihvola E, Korhonen T, Pulkkinen L, Moilanen I, Kaprio J, Rose RJ, Dick DM. Depressive symptoms and alcohol use are genetically and environmentally correlated across adolescence. Behav Genet. 2011;41:47687.

102. Jacob L, Haro JM, Koyanagi A. Relationship between living alone and common mental disorders in the 1993, 2000 and 2007 National Psychiatric Morbidity Surveys. PLoS One. 2019;14(5):e0215182.

103. Elovainio $M$, Hakulinen $C$, Pulkki-Råback L, Aalto AM, Virtanen M, Partonen T, Suvisaari J. General Health Questionnaire (GHQ-12), Beck Depression Inventory (BDI-6), and Mental Health Index (MHI-5): psychometric and predictive properties in a Finnish population-based sample. Psychiatry Res. 2020;289:112973. doi:10.1016/j.psychres.2020.112973. Epub ahead of print. PMID: 32413708.

104. Althubaiti A. Information bias in health research: definition, pitfalls, and adjustment methods. J Multidiscip Healthc. 2016;9:211-7.

\section{Tables}


Table 1

Characteristics of the sample by gender (numbers, percentages, means, and $95 \%$ confidence intervals)

\begin{tabular}{|c|c|c|c|}
\hline & $\begin{array}{l}\text { Men } \\
(n=15,140)\end{array}$ & $\begin{array}{l}\text { Women } \\
(n=18,112)\end{array}$ & $P$ value \\
\hline & $\mathrm{n}(\%)$ & n (\%) & \\
\hline MHI-5 (cut-off < = 52 points) & $1,321(8.8)$ & $1,984(11.0)$ & $<0.0001$ \\
\hline \multirow[t]{2}{*}{$\mathrm{MHI}-5$ mean $(95 \% \mathrm{Cl})$} & $75.8(75.6-$ & $74.4(74.1-$ & \\
\hline & 76.1) & 74.6) & \\
\hline Age (years) & $3,496(28.7)$ & $3,852(24.5)$ & $<0.0001$ \\
\hline $20-34$ & $5,834(39.7)$ & $6,791(38.2)$ & \\
\hline $35-49$ & $6,322(31.6)$ & $8,087(37.4)$ & \\
\hline $50-65$ & $42.4(42.2-$ & $43.9(43.7-$ & \\
\hline Age (mean) & 42.6) & 44.0) & \\
\hline Education (years) & $6,224(43.0)$ & $4,793(26.9)$ & $<0.0001$ \\
\hline$k=12$ & $5,367(33.6)$ & $8,089(43.4)$ & \\
\hline $13-16$ & $4,061(23.4)$ & $5,849(29.7)$ & \\
\hline \multicolumn{4}{|l|}{$17+$} \\
\hline Marital status & $12,016(76.1)$ & $13,495(72.9)$ & $<0.0001$ \\
\hline Married/cohabiting & $1,017(6.7)$ & $2,255(12.3)$ & \\
\hline Separated/divorced/widowed & $2,105(17.2)$ & $2,360(14.8)$ & \\
\hline \multicolumn{4}{|l|}{ Single } \\
\hline Lives alone & $2,011(14.5)$ & $2,703(14.9)$ & 0.263 \\
\hline Yes & $13,641(85.5)$ & $16,028(85.1)$ & \\
\hline \multicolumn{4}{|l|}{ No } \\
\hline Has children under 18 years of age & $1,605(21.9)$ & $840(9.7)$ & $<0.0001$ \\
\hline$<3$ years old & $2,032(26.2)$ & $1,903(20.2)$ & $<0.0001$ \\
\hline 3 to 6 years old & $4,459(44.8)$ & $5,277(44.2)$ & 0.373 \\
\hline \multicolumn{4}{|l|}{7 to 17 years old } \\
\hline At-risk drinking (AUDIT-C) $\left.{ }^{1}\right)$ & $5,678(37.5)$ & $4,087(22.8)$ & $<0.0001$ \\
\hline
\end{tabular}

1) At-risk drinking is assessed as AUDIT-C, men $>=6$ points and women $>=5$ points.

2) $\mathrm{N}$ indicates the number of yes answers. 


\begin{tabular}{|c|c|c|c|}
\hline & $\begin{array}{l}\text { Men } \\
(n=15,140)\end{array}$ & $\begin{array}{l}\text { Women } \\
(n=18,112)\end{array}$ & $P$ value \\
\hline Current smoker & $2,350(25.6)$ & $2,346(23.0)$ & $<0.0001$ \\
\hline Loneliness & $14,424(94.1)$ & $16,988(92.7)$ & $<0.0001$ \\
\hline Never/seldom/sometimes & $810(5.9)$ & $1,273(7.3)$ & \\
\hline \multicolumn{4}{|l|}{ Quite often/all the time } \\
\hline Active member in societies, hobby groups, etc. & $4,609(28.9)$ & $5,318(28.1)$ & 0.0962 \\
\hline Difficulty in covering household costs & $3,583(25.2)$ & $4,567(26.5)$ & 0.011 \\
\hline How many persons give you practical help? & $217(1.6)$ & $201(1.2)$ & 6.64 \\
\hline No one & $8,303(54.4)$ & $9,697(53.5)$ & 0.0013 \\
\hline $1-2$ persons & $6,412(43.0)$ & $7,957(45.3)$ & \\
\hline \multicolumn{4}{|l|}{$3-6$ persons } \\
\hline How many persons give you emotional support? & $150(1.1)$ & $146(0.8)$ & $<0.0001$ \\
\hline No one & $9,725(63.8)$ & $9,639(53.4)$ & \\
\hline $1-2$ persons & $5,096(35.1)$ & $8,108(45.8)$ & \\
\hline \multicolumn{4}{|l|}{$3-6$ persons } \\
\hline Helping someone outside the household regularly, at least once a month & $4,629(41.3)$ & $5,846(44.3)$ & $<0.0001$ \\
\hline Parent & $3,204(28.6)$ & $4,691(36.6)$ & $<0.0001$ \\
\hline Child & $3,394(32.5)$ & $4,921(39.3)$ & $<0.0001$ \\
\hline \multicolumn{4}{|l|}{ Other } \\
\hline Work satisfaction & $2,889(18.6)$ & $3,883(20.9)$ & $<0.0001$ \\
\hline Extremely satisfied & $8,664(56.0)$ & $10,420(56.6)$ & \\
\hline Fairly satisfied & $2,508(16.8)$ & $2,547(14.2)$ & \\
\hline Neither satisfied nor dissatisfied & $1,233(8.6)$ & $1,431(8.2)$ & \\
\hline Fairly - extremely dissatisfied & & & \\
\hline
\end{tabular}

1) At-risk drinking is assessed as AUDIT-C, men $>=6$ points and women $>=5$ points.

2) $\mathrm{N}$ indicates the number of yes answers. 


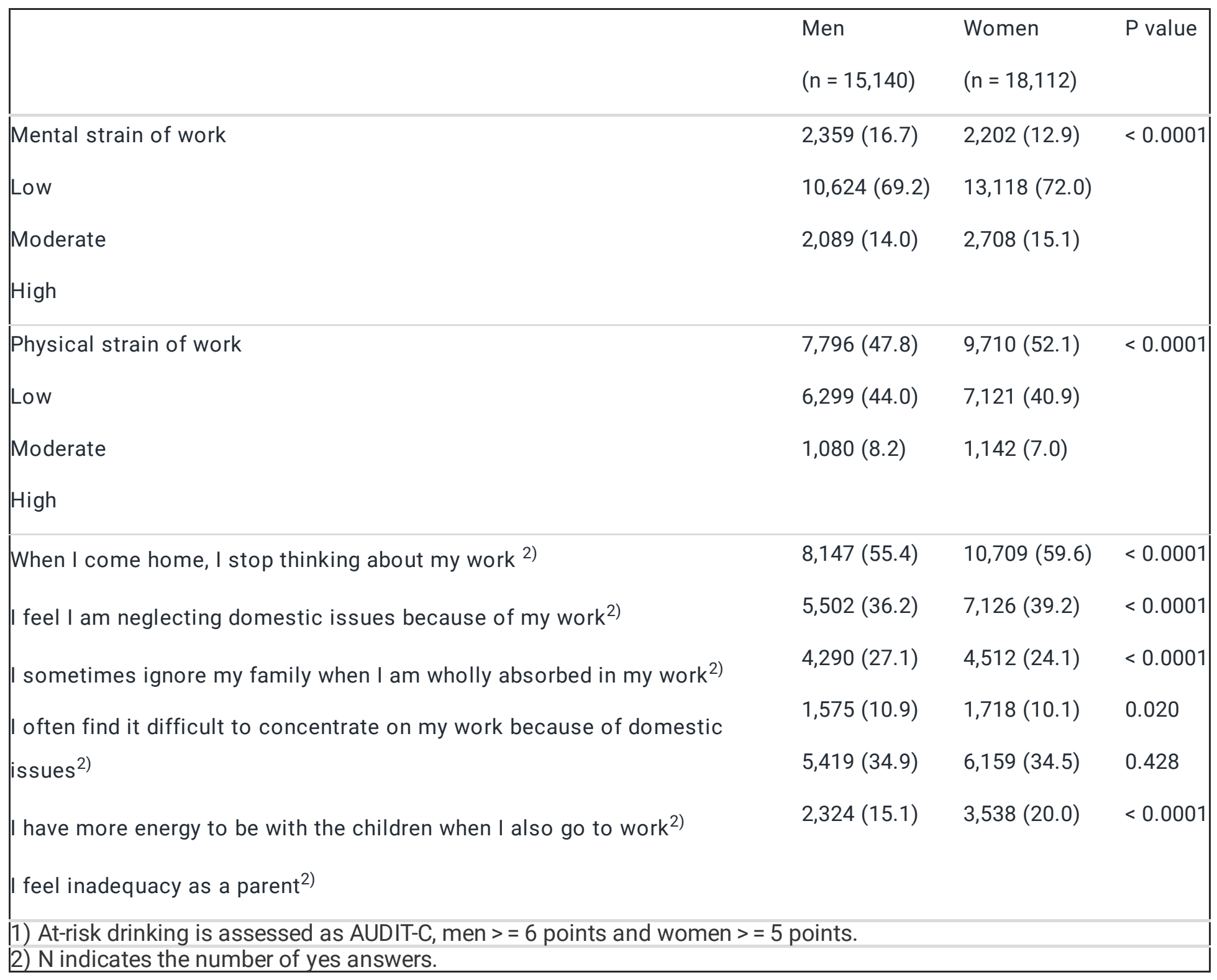

Table 2. Associations of study variables with psychological distress by gender (MHI5 cut-off <=52) $(\%)$ 


\begin{tabular}{|c|c|c|c|c|c|c|}
\hline & \multicolumn{3}{|l|}{ Men $(\mathrm{N}=15,059)$} & \multicolumn{3}{|c|}{ Women $(\mathrm{N}=18,050)$} \\
\hline & $\begin{array}{l}\text { Psychological } \\
\text { distress } \\
(\mathrm{N}=1,321)\end{array}$ & $\begin{array}{l}\text { No } \\
\text { psychological } \\
\text { distress } \\
(\mathrm{N}=13,738)\end{array}$ & & $\begin{array}{l}\text { Psychological } \\
\text { distress } \\
(\mathrm{N}=1,984)\end{array}$ & $\begin{array}{l}\text { No } \\
\text { psychological } \\
\text { distress } \\
(\mathrm{N}=16,066)\end{array}$ & \\
\hline$\%$ & $\%(\mathrm{~N})$ & $\%(\mathrm{~N})$ & $P$ value & $\%(\mathrm{~N})$ & $\%(\mathrm{~N})$ & $\mathrm{P}$ value \\
\hline \multicolumn{7}{|l|}{ Age group (years) } \\
\hline $20-34(21.4)$ & $12.0(388)$ & $88.0(2,977)$ & \multirow[t]{3}{*}{$<0.0001$} & $15.6(554)$ & $84.4(3,138)$ & \multirow[t]{3}{*}{$<0.0001$} \\
\hline $35-49(36.7)$ & $9.6(507)$ & $90.4(5,103)$ & & $10.9(688)$ & $89.1(5,865)$ & \\
\hline $50-65(41.9)$ & $7.5(426)$ & $92.5(5,658)$ & & $9.9(742)$ & $90.1(7,063)$ & \\
\hline \multicolumn{7}{|l|}{ Education years } \\
\hline$<=12(32.0)$ & $10.0(541)$ & $90.0(5,355)$ & \multirow[t]{3}{*}{0.0756} & $13.1(548)$ & $86.9(3,992)$ & \multirow[t]{3}{*}{0.0013} \\
\hline $13-16(39.1)$ & $9.9(464)$ & $90.1(4,753)$ & & $11.5(844)$ & $88.5(6,982)$ & \\
\hline $17+(28.9)$ & $8.6(316)$ & $91.4(3,630)$ & & $10.7(592)$ & $89.3(5,093)$ & \\
\hline \multicolumn{7}{|l|}{ Marital status } \\
\hline Married/cohabiting (76.7) & $8.1(879)$ & $91.9(10,743)$ & \multirow[t]{3}{*}{$<0.0001$} & $10.0(1,238)$ & $90.0(11,814)$ & \multirow[t]{3}{*}{$<0.0001$} \\
\hline Separated/divorced/widowed & $14.2(123)$ & $85.8(11,622)$ & & $14.7(308)$ & $85.3(1,879)$ & \\
\hline (9.9) & $14.5(280)$ & $85.5(1,746)$ & & $16.7(365)$ & $83.3(1,895)$ & \\
\hline \multicolumn{7}{|l|}{ Single (13.4) } \\
\hline \multicolumn{7}{|l|}{ Lives alone } \\
\hline Yes (13.7) & $14.7(262)$ & $85.3(1,690)$ & \multirow[t]{2}{*}{$<0.0001$} & $15.4(385)$ & $84.6(2,243)$ & \multirow[t]{2}{*}{$<0.0001$} \\
\hline No (86.3) & $8.7(1059)$ & $91.3(12,048)$ & & $11.0(1,599)$ & $89.0(13,824)$ & \\
\hline \multicolumn{7}{|c|}{ Has children under 18 years of } \\
\hline age & $8.6(498)$ & $91.4(5,565)$ & \multirow[t]{2}{*}{$<0.0001$} & $11.1(674)$ & $88.9(5,699)$ & \multirow[t]{2}{*}{0.0023} \\
\hline Yes (53.1) & $11.6(495)$ & $88.4(4,232)$ & & $12.9(777)$ & $87.1(5604)$ & \\
\hline \multicolumn{7}{|l|}{ No $(46.9)$} \\
\hline \multicolumn{7}{|l|}{ At-risk drinking ${ }^{1)}$} \\
\hline Yes (28.4) & $12.0(606)$ & $88.0(4,930)$ & \multirow[t]{2}{*}{$<0.0001$} & $15.2(574)$ & $84.8(3,414)$ & $<0.0001$ \\
\hline No $(71.6)$ & $8.1(705)$ & $91.9(8,808)$ & & $10.6(1,410)$ & $89.4(12,653)$ & \\
\hline Current smoker & & & & & & \\
\hline Yes (22.3) & $13.6(291)$ & $86.4(1,987)$ & $<0.0001$ & $19.2(411)$ & $80.8(1,869)$ & $<0.0001$ \\
\hline No (77.7) & $8.6(646)$ & $91.4(6,908)$ & & $10.7(900)$ & $89.3(7,503)$ & \\
\hline Loneliness & & & & & & \\
\hline Never/seldom/sometimes & $7.1(933)$ & $92.9(13,285)$ & $<0.0001$ & $8.8(1,394)$ & $91.2(15,381)$ & $<0.0001$ \\
\hline$(93.8)$ & $49.3(385)$ & $50.7(409)$ & & $48.1(587)$ & $51.9(669)$ & \\
\hline Often/all the time (6.2) & & & & & & \\
\hline $\begin{array}{l}\text { Active member in societies, } \\
\text { hobby groups, etc.? }\end{array}$ & & & & & & \\
\hline Yes (29.5) & $6.9(283)$ & $93.1(4,182)$ & $<0.0001$ & $8.0(397)$ & $92.0(4,775)$ & $<0.0001$ \\
\hline No $(70.5)$ & $10.7(1,020)$ & $89.3(9,367)$ & & $13.1(1,553)$ & $86.9(11,021)$ & \\
\hline $\begin{array}{l}\text { How difficult or easy is it to } \\
\text { cover household costs? }\end{array}$ & & & & & & \\
\hline fairly difficult/very difficult & $29.0(251)$ & $71.0(655)$ & $<0.0001$ & $29.2(369)$ & $70.8(914)$ & $<0.0001$ \\
\hline$(24.0)$ & $8.2(1,063)$ & $91.8(12,998)$ & & $10.1(1,592)$ & $89.9(15,013)$ & \\
\hline fairly easy / very easy (76.0) & & & & & & \\
\hline How many persons give you & & & & & & \\
\hline practical help? & $39.8(77)$ & $60.2(128)$ & $<0.0001$ & $40.8(75)$ & $59.2(119)$ & $<0.0001$ \\
\hline No one (1.3) & $11.8(863)$ & $88.2(7,215)$ & & $13.9(1,223)$ & $86.1(8,161)$ & \\
\hline $1-2$ persons (54.9) & $5.8(331)$ & $94.2(5,890)$ & & $8.1(593)$ & $91.9(7,187)$ & \\
\hline $3-6$ persons (43.8) & & & & & & \\
\hline How many persons give you & & & & & & \\
\hline emotional support? & $40.9(54)$ & $59.1(85)$ & $<0.0001$ & $45.2(61)$ & 54.8 (79) & $<0.0001$ \\
\hline No one (0.9) & $10.9(931)$ & $89.1(8,531)$ & & $13.8(1,206)$ & $86.2(8,120)$ & \\
\hline $1-2$ persons (58.9) & $6.2(288)$ & $93.8(4,646)$ & & $8.3(628)$ & $91.7(7,291)$ & \\
\hline $3-6$ persons $(40.2)$ & & & & & & \\
\hline
\end{tabular}

Helping a parent outside the 
household regularly, at least

once a month

Yes (42.9)

No (57.1)

Helping a child outside the

household regularly, at least

\section{once a month}

Yes (34.6)

No (65.4)

Helping someone else outside

the household regularly, at

least once a month

Yes (35.1)

No (64.9)

Work satisfaction

extremely satisfied (20.2)

fairly satisfied (56.8)

neither satisfied nor

dissatisfied (15.1)

fairly/extremely dissatisfied

(7.9)

Mental strain of work

Low (13.8)

Moderate (71.7)

High (14.5)

Physical strain of work

Low (52.8)

Moderate (40.5)

High (6.7)

When I come home, I stop

thinking about my work

Yes (56.3)

No (43.7)

I feel that I am neglecting domestic issues because of

my work

Yes (37.8)

No (62.2)

I sometimes ignore my family when I am wholly absorbed in

my work

Yes (26.4)

No (73.6)

I often find it difficult to

concentrate on my work

because of domestic issues

Yes (9.9)

No (90.1)

I have more energy to be with the children when I also go to work

Yes (35.1)

No (64.9)

I feel inadequacy as a parent

Yes (17.8)

No (82.2)

$\begin{array}{llllll}9.1(382) & 90.9(4,099) & 0.0077 & 11.7(634) & 88.3(5,067) & 0.1040 \\ 10.7(649) & 89.3(5,789) & & 12.6(859) & 87.4(6,273) & \end{array}$

$\begin{array}{llllll}9.3(264) & 90.7(2,837) & 0.0774 & 11.1(486) & 88.9(4,077) & 0.0075\end{array}$

$10.5(706) \quad 89.5(6,332) \quad 12.8(913) \quad 87.2(6,554)$

$10.6(323)$

$89.4(2,960)$

0.299

$13.6(617)$

$86.4(4,165)$

0.0008

$9.9(687)$

$90.1(6,614)$

$11.5(852)$

$88.5(6,857)$

$3.8(93)$

$6.2(467)$

15.3 (357)

$96.2(2,720)$

$<0.0001$

$5.0(168)$

$8.7(836)$

19.3 (465)

$84.7(2,069)$

$33.7(387)$

66.3 (811)

36.4 (490)

$95.0(3,620)$

$<0.0001$

$91.3(9,300)$

$80.7(2,008)$

$63.6(895)$

$4.4(90)$

7.9 (737)

$95.6(2,212)$

$<0.0001$

$6.0(112)$

$9.7(1,160)$

$94.0(2,024)$

$<0.0001$

26.0 (663)

$90.3(11,622)$

$92.1(9,602)$
$75.6(1,561)$

74.0 (1974)

$8.3(582)$

$9.2(524)$

$91.7(7,040)$

$<0.0001$

$10.4(926)$

$11.8(775)$

$89.6(8,549)$

$88.2(6,136)$

19.1 (187)

80.9 (853)

$21.0(226)$

79.0 (874)

$6.9(492)$

13.0 (814)

$93.1(7,440)$

$<0.0001$

$8.1(787)$

$16.9(1,168)$

$91.9(9,621)$

$83.1(6,185)$

$<0.0001$

15.5 (761)

$84.5(4,583)$

$93.7(8,957)$

$<0.0001$

$18.5(1,221)$

7.3 (729)

$81.5(5,729)$

$92.7(10,053)$

$<0.0001$

$14.4(549)$

$7.8(751)$

$85.6(3,625)$

$92.2(9,883)$

$<0.0001$

$18.9(786)$

$9.3(1,160)$

$81.1(3,622)$

$90.7(12,146)$

$<0.0001$

$28.7(419)$

$71.3(1,106)$

$<0.0001$

$34.5(556)$

$9.1(1,395)$

$65.5(1,118)<0.0001$

$92.7(12,425)$

$90.9(14,651)$

$6.9(350)$

11.1 (936)

$93.1(4,928)$

$88.9(8,425)$

$<0.0001$

$9.8(563)$

$12.7(1,362)$

$90.2(5,423)$

$87.3(10,147)$

$20.6(439)$

$79.4(1,824)$

$92.3(11,546)$
$<0.0001 \quad 20.8$ (686)

$9.4(1243)$
$79.2(2,756)$

$90.6(12,830)$

$<0.0001$ 
1) At-risk drinking is assessed as AUDIT-C, men $>=6$ points and women $>=5$ points.

Calculated using the inverse probability weights (see Methods).

Table 3. Logistic regression analysis (odds ratios with $95 \%$ confidence intervals) of non-work-related and work-related factors with psychological distress (MHI- 5 cut-off $<=52$ points) in the working-age population. Variables were included in the model simultaneously. 


\begin{tabular}{|c|c|c|c|c|}
\hline & $\begin{array}{l}\text { Men } \\
(\mathrm{N}=15,357)\end{array}$ & & $\begin{array}{l}\text { Women } \\
(\mathrm{N}=18,271)\end{array}$ & \\
\hline & OR $(95 \% \mathrm{Cl})$ & P value & OR $(95 \% \mathrm{Cl})$ & P value \\
\hline Sociodemographic factors & & & & \\
\hline Age (years) & & & & \\
\hline $20-34$ & $1.28(0.86-$ & 0.23 & $1.39(0.97-$ & 0.07 \\
\hline $35-49$ & 1.92) & 0.72 & $2.00)$ & 0.38 \\
\hline $50-65$ & $1.07(0.75-$ & & $1.16(0.84-$ & \\
\hline & 1.53) & & $1.60)$ & \\
\hline & 1.00 & & 1.00 & \\
\hline Education (years) & & & & \\
\hline$<=12$ & $0.79(0.56-$ & 0.18 & $1.09(0.80-$ & 0.58 \\
\hline $13-16$ & 1.11) & 0.51 & 1.49) & 0.89 \\
\hline $17+$ & $0.90(0.67-$ & & $0.98(0.77-$ & \\
\hline & $1.23)$ & & 1.26) & \\
\hline & 1.00 & & 1.00 & \\
\hline Marital status & & & & \\
\hline Married/cohabiting & 1.00 & & 1.00 & \\
\hline Divorced/separated/widowed & $1.02(0.60-$ & 0.95 & $1.09(0.75-$ & 0.65 \\
\hline Single & 1.71) & 0.31 & $1.57)$ & 0.88 \\
\hline & $\begin{array}{l}1.33(0.77- \\
2.33)\end{array}$ & & $\begin{array}{l}1.03(0.68- \\
1.56)\end{array}$ & \\
\hline Other not work-related factors & & & & \\
\hline Lives alone & $\begin{array}{l}0.71(0.42- \\
1.22)\end{array}$ & 0.21 & $\begin{array}{l}1.26(0.83- \\
1.91)\end{array}$ & 0.28 \\
\hline Has children under 18 years of age & $\begin{array}{l}0.69(0.50- \\
0.96)\end{array}$ & 0.0075 & $\begin{array}{l}0.79(0.58- \\
1.07)\end{array}$ & 0.13 \\
\hline At-risk drinking ${ }^{1}$ ) & $\begin{array}{l}1.40(1.10- \\
1.78)\end{array}$ & 0.0057 & $\begin{array}{l}1.16(0.92- \\
1.46)\end{array}$ & 0.21 \\
\hline Current smoker & $\begin{array}{l}1.46(1.09- \\
1.94)\end{array}$ & 0.0103 & $\begin{array}{l}1.40(1.09- \\
1.81)\end{array}$ & 0.0091 \\
\hline Lonely quite often or all the time & $\begin{array}{l}6.20(4.17- \\
9.20)\end{array}$ & $<0.0001$ & $\begin{array}{l}6.06(4.51- \\
8.13)\end{array}$ & $<0.0001$ \\
\hline Active member in societies, hobby groups, etc. & $\begin{array}{l}0.88(0.67- \\
1.16)\end{array}$ & 0.37 & $\begin{array}{l}0.68(0.53- \\
0.88)\end{array}$ & 0.0034 \\
\hline Difficulty in covering household costs & $\begin{array}{l}1.68(1.31- \\
2.16)\end{array}$ & 0.0001 & $\begin{array}{l}1.70(1.36- \\
2.11)\end{array}$ & $<0.0001$ \\
\hline How many persons give you practical help? & & & & \\
\hline No one & 1.00 & & 1.00 & \\
\hline $1-2$ persons & $0.40(0.20-$ & 0.01 & $0.72(0.34-$ & 0.39 \\
\hline $3-6$ persons & $0.81)$ & 0.004 & 1.53) & 0.23 \\
\hline & $0.35(0.17-$ & & $0.62(0.28-$ & \\
\hline & $0.71)$ & & 1.35) & \\
\hline How many persons give you emotional support & & & & \\
\hline No one & 1.00 & & 1.00 & \\
\hline $1-2$ persons & $0.83(0.31-$ & 0.72 & $0.41(0.15-$ & 0.09 \\
\hline $3-6$ persons & $2.22)$ & 0.20 & 1.14) & 0.04 \\
\hline & $\begin{array}{l}0.51(0.19- \\
1.43)\end{array}$ & & $\begin{array}{l}0.34(0.12- \\
0.97)\end{array}$ & \\
\hline Helping parents outside the home & $\begin{array}{l}0.78(0.61- \\
1.01)\end{array}$ & 0.0569 & $\begin{array}{l}1.06(0.86- \\
1.32)\end{array}$ & 0.57 \\
\hline Helping children outside the home & $\begin{array}{l}0.82(0.62- \\
1.09)\end{array}$ & 0.17 & $\begin{array}{l}0.93(0.74- \\
1.17)\end{array}$ & 0.55 \\
\hline Helping someone else outside the home & $\begin{array}{l}1.05(0.80- \\
1.38)\end{array}$ & 0.70 & $\begin{array}{l}1.20(0.96- \\
1.50)\end{array}$ & 0.11 \\
\hline
\end{tabular}


Work satisfaction

Extremely satisfied

1.00

Fairly satisfied

Neither satisfied nor dissatisfied

1.70 (1.11-

2.60)

$2.96(1.88-$

4.66)

$6.61(4.14-$

11.55)

Mental strain of work

Low

1.00

Moderate

$1.31(0.84-$

High

2.03)

$2.71(1.66-$

4.41)

Physical strain of work

Low

1.00

Moderate

High

$0.90(0.69-$

1.18)

$1.19(0.78-$

1.80)

When I come home, I stop thinking about my work ${ }^{2)}$

$0.64(0.50-$

0.83)

I feel I am neglecting domestic issues because of my work ${ }^{2}$ )

$1.53(1.14-$ 2.04)

I sometimes ignore my family when I am wholly absorbed in my work ${ }^{2}$

$0.94(0.69-$

1.27)

I often find it difficult to concentrate on my work because of domestic issues ${ }^{2}$ )

$3.24(2.42-$ 4.32)

I have more energy to be with the children when I also go to work ${ }^{2)}$

$0.72(0.54-$

0.95)

\begin{tabular}{|c|c|c|}
\hline & 1.00 & \\
\hline $\begin{array}{l}0.01 \\
<0.0001 \\
<0.0001\end{array}$ & $\begin{array}{l}1.74(1.24- \\
2.44) \\
2.35(1.58- \\
3.51) \\
6.08(4.09- \\
9.04)\end{array}$ & $\begin{array}{l}0.001 \\
<0.0001 \\
<0.0001\end{array}$ \\
\hline & 1.00 & \\
\hline 23 & $0.97(0.68-$ & 0.89 \\
\hline 0001 & $\begin{array}{l}1.41) \\
1.34(0.88- \\
2.04)\end{array}$ & 0.17 \\
\hline & 1.00 & \\
\hline 46 & $0.84(0.66-$ & 0.13 \\
\hline 10 & $\begin{array}{l}1.05) \\
0.86(0.57- \\
1.28)\end{array}$ & 0.45 \\
\hline 0008 & $\begin{array}{l}0.58(0.46-0- \\
73)\end{array}$ & $<0.0001$ \\
\hline 004 & $\begin{array}{l}1.60(1.25- \\
2.04)\end{array}$ & 0.0002 \\
\hline 67 & $\begin{array}{l}1.30(1.00- \\
1.70)\end{array}$ & 0.0497 \\
\hline 02 & $\begin{array}{l}2.70(2.08- \\
3.49)\end{array}$ & $<0.0001$ \\
\hline 0.0001 & $\begin{array}{l}0.77(0.59- \\
0.99)\end{array}$ & 0.047 \\
\hline$n$ & $\begin{array}{l}2.04(1.57- \\
2.64)\end{array}$ & $<0.0001$ \\
\hline
\end{tabular}

I feel inadequacy as a parent ${ }^{2}$ )

$2.21(1.64-$ 2.98)

1) At-risk drinking is assessed as AUDIT-C, men $>=6$ points and women $>=5$ points.

2) $\mathrm{N}$ indicates the number of yes answers.

OR=Odds ratio, $95 \% \mathrm{Cl}=95 \%$ confidence interval

Bold ratios: statistically significant results

Variables were included in the model simultaneously

\section{Figures}




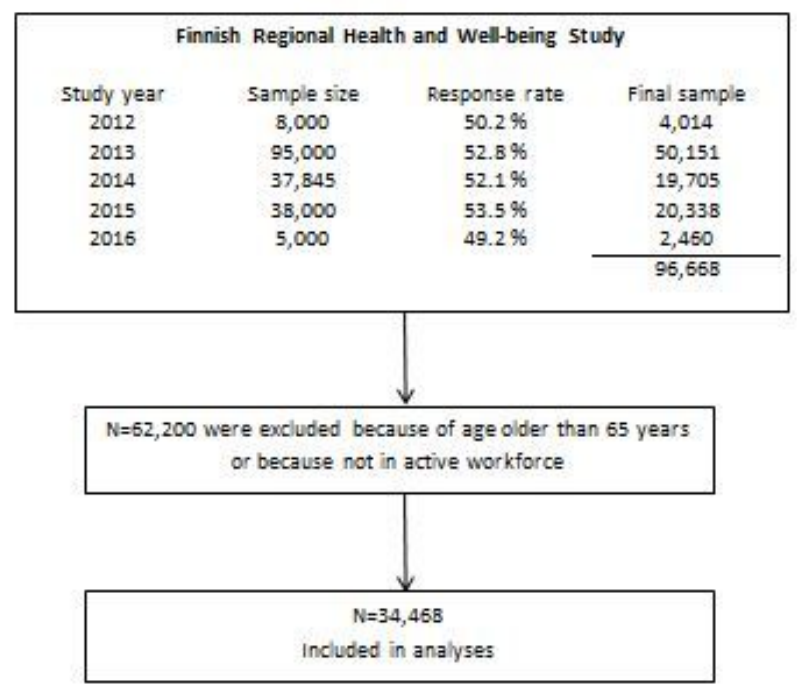

\section{Figure 1}

Flow chart of the sample sizes and response rates to the Finnish Regional Health and Well-being Study and participants in the present study.

\section{Supplementary Files}

This is a list of supplementary files associated with this preprint. Click to download.

- Questionnaire.docx 